\title{
Normal Variant Distribution among Elderly Patients Who Visited Airlangga University Dental Hospital
}

\author{
Rosaline Novita Irianna Krimadi, DDS, MPH, Nurina Febriyanti Ayuningtyas, DDS, MDS, PhD \\ and Adiastuti Endah Parmadiati, DDS, MDS \\ Department of Oral Medicine, Faculty of Dental Medicine, Universitas Airlangga, Surabaya, Indonesia
}

\begin{abstract}
Background and Objective. A normal variant of the oral cavity in humans, especially when aging, indicates how the body adapts to the environment, a lifestyle, and irritation. This study aimed to examine the distribution of normal variants among elderly patients who visited Airlangga University Dental Hospital.

Method. This was a descriptive observational design study. Examination of oral soft tissue was performed on elderly dental patients who came to the hospital from January to December 2019.

Results. Sixty-eight (68) elderly patients, 60 years of age and over, 35 males and 33 females. The study identified 138 normal oral variations of soft tissues and oral structures. The three highest distributions obtained were coated tongue, lingual varicosities, and fissured tongue.
\end{abstract}

Conclusion. The normal variants of oral mucosa and oral structure in the elderly resulted from how the body adapted to the environment and the awareness of the systemic disease that might occur.

Key Words: normal variant, elderly patients, oral hygiene

\section{INTRODUCTION}

Aging, a process that affects every living creature, including humans without any exception, is an accumulation of activities involving body changes during an increase of age, with marks by deleterious cells and tissues, with structures inside the mouth showing some changes in any part of the body. ${ }^{1}$ For example, in the nervous system, cognitive, memory learning, and special senses as vision, hearing, taste, smell, and touch, even changes involving the musculoskeletal and the entire body. ${ }^{2}$

The aging process itself, when it happens significantly by age, is not categorized as a disease. The aging process can happen at any age level. Unfortunately, not everyone has self-awareness of the change of their body, primarily if it occurs inside the body until symptoms appear in one or more body organs. The consideration of aging sometimes even did not recognize by physicians or dentists when they examine their patients. Some aging processes can be a sign of systemic disease, and sometimes aging can be caused by an alteration in body structure. ${ }^{3}$

One part of the body that is directly affected by the aging process is the oral cavity. Changes in the structure of the oral cavity also affect the overall function of the body. The normal variant lesion of the oral cavity in humans, especially in the elderly, indicates how their bodies adapt 
to the environment, lifestyle, and irritation on their body. The changing structure and function in the oral mucosal or stomatognathic system could be a sign or a symptom of a bad habit or even a systemic disease. It is necessary to know the disease and differentiate between the disease itself and the normal condition of the oral mucosal. ${ }^{3}$

This study aimed to examine the distribution of normal variants among elderly patients who visited Airlangga University Dental Hospital in 2019 due to early detection and prevention of a possible systemic disease.

\section{METHOD}

The research was conducted on elderly patients. This design was a descriptive observational study. Data of normal variant lesions were collected retrospectively using secondary data from medical records of patients who visited Airlangga University Dental Hospital from January to December 2019 (No ethical approval was needed).

Inclusion criteria were elderly patients with an age range of 60 years old and more, while exclusion criteria were elderly patients below 60 years of age.

The examination was carried out by an examiner involved with students currently undergoing dental education and a Resident at the Department of Oral Medicine Airlangga University who was on duty in the triage room of the Airlangga University Dental Hospital in Surabaya.

The data were grouped according to age and sex and the types of normal variations encountered, and the proportion was computed and interpreted.

\section{RESULTS}

The total number of patients who visited Dental Hospital Airlangga University was 1180 in 2019. Presented in this section are the results of this study.

Of the 1180 patients who visited Dental Hospital Airlangga University, 68 were elderly, 35 males and 33 females (Table 1).

Figure 1 shows the clinical manifestation of a normal variant of the oral mucosa. The first figure (A) shows white pseudomembrane lesion as a characteristic of the coated tongue, while blue-black dilated tortuous vessels as a sign of lingual varicosities (B). The last figure shows multiple fissures on the dorsal tongue, manifesting a fissured tongue (C).

From the 68 elderly patients, 138 normal variants were found and grouped based on the variant (Table 2).

The three highest prevalence of normal variant lesions of oral mucosa found in the elderly were coated tongue $(n=25$, $18 \%)$, followed by sublingual varicosities $(\mathrm{n}=22,16 \%)$, and fissured tongue $(\mathrm{n}=19,14 \%)$.
Table 1. The distribution of normals variants lesion according to age and sex

\begin{tabular}{crccc} 
Ages Group & \multicolumn{2}{c}{ Gender } & Total patient & Percentage \\
\cline { 2 - 3 } (years) & Male & Female & screened & $3 \%$ \\
$<10$ & 19 & 16 & 35 & $3 \%$ \\
$11-20$ & 69 & 115 & 184 & $16 \%$ \\
$21-30$ & 191 & 258 & 449 & $38 \%$ \\
$31-40$ & 59 & 99 & 158 & $13 \%$ \\
$41-50$ & 72 & 103 & 175 & $15 \%$ \\
$51-60$ & 45 & 66 & 111 & $9 \%$ \\
$>60$ & 35 & 33 & 68 & $6 \%$ \\
\hline Total & 490 & 690 & 1180 & \\
\hline
\end{tabular}

Table 2. The distribution of normal variant lesions among elderly patients $>60$ years $(N=68)$

\begin{tabular}{lcc} 
Normal Variant Oral Lesion & $\begin{array}{c}\text { Number of } \\
\text { Patients }\end{array}$ & Percentage \\
\hline Coated tongue & 25 & $18 \%$ \\
Sublingual varicosities & 22 & $16 \%$ \\
Fissured tongue & 19 & $14 \%$ \\
Torus (palatinus dan mandibularis) & 13 & $9 \%$ \\
Geographic tongue & 8 & $6 \%$ \\
Linea alba buccalis & 8 & $6 \%$ \\
Crenated tongue & 7 & $5 \%$ \\
Ductus stenoni prominent & 7 & $5 \%$ \\
Ankyloglossia & 4 & $3 \%$ \\
Frictional keratosis & 4 & $3 \%$ \\
Fordyce's spots & 4 & $3 \%$ \\
Papilla prominent & 3 & $2 \%$ \\
Macro/microglossia & 2 & $1 \%$ \\
Hairy tongue & 2 & $1 \%$ \\
Morsicatio buccarum (cheek biting) & 2 & $1 \%$ \\
Normal hyperpigmentation & 2 & $1 \%$ \\
Nevus pigemntosus/ptechiae & 2 & $1 \%$ \\
Exostosis & 2 & $1 \%$ \\
Bifid tongue & $1 \%$ \\
Leukoedema & 0 & $1 \%$ \\
Median rhomboid glossitis & 0 & $0 \%$ \\
Nicotine stomatitis & $0 \%$ \\
White sponge nevus & $0 \%$ \\
Heavy metal induced & $0 \%$ \\
hyperpigmentation & $0 \%$ \\
Srug induced hyperpigmentation & 0 Ephelis & $0 \%$ \\
\hline
\end{tabular}



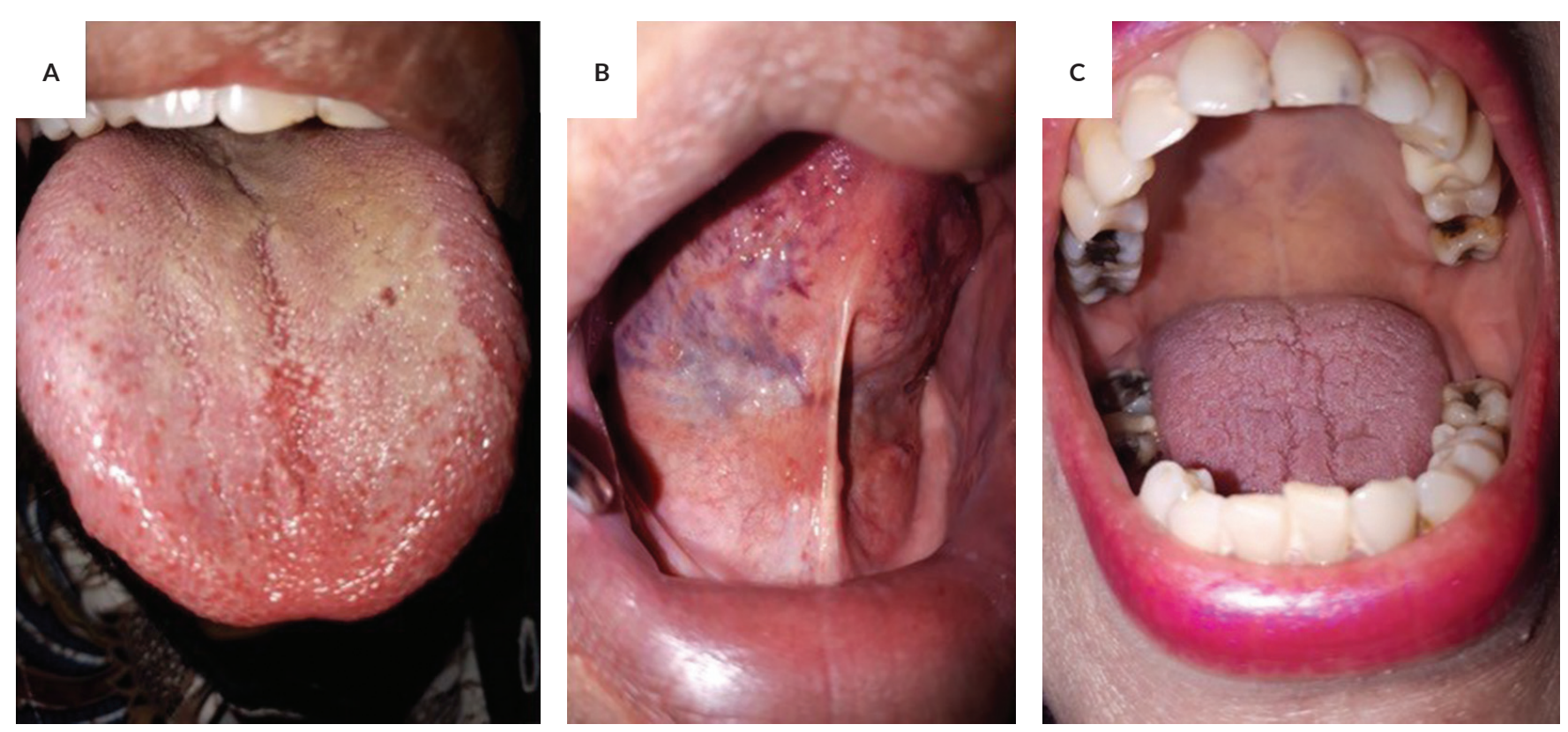

Figure 1. Clinical lesion variation was found: coated tongue (A), sublingual varicosities (B), and fissured tongue (C).

\section{DISCUSSION}

Coated tongue as high as $18 \%$ was the highest number of lesions found in elderly patients who came to the Dental Hospital of Airlangga University Surabaya. This was similar to the results of $55.56 \%$ in research conducted by Mahdani et al. in 2018. ${ }^{4}$ Second highest lesion with a $16 \%$ rate was sublingual varicosities. Sublingual varicosities are normal variations that are usually in elderly patients. Although generally due to aging, some sublingual varicosities veins represent a systemic problem in a person, for example, if the patient has a history of the cardiovascular disorder or diabetes mellitus. ${ }^{5}$

Fissure tongue, a normal variation with deep grooves, and fissure with varying size and depth on the dorsal surface of the tongue are the third most lesions, as high as $14 \%$ with unknown certainty. ${ }^{6-8}$ In some cases, it is associated with syndromes such as Melkersson-Rosenthal, Coffin-Lowry, Fraser's, Downs, Type I Oral-Facial Digital, Mohr's, Pierre Robin, Maroteaux-Lamy, EctrodactylyEctodermal Dysplasia-Clefting (ECC) and Sjogren. ${ }^{9}$

Meanwhile, torus palatinus, with a $9 \%$ rate, does not have a fundamental relationship with age. The theory of the form of torus palatinus is due to genetic and multifactor. Some of the normal variants occurring in the oral cavity have a relationship with how persons maintain their oral hygiene and a connection with systemic disease or clinical sign dentist should be more concerned. ${ }^{10}$

A coated tongue is a condition when the tongue is covered with a layer that has a composition that includes bacteria, desquamated epithelium, leukocytes from periodontal pockets, and metabolites and food debris. ${ }^{6} \mathrm{~A}$ coated tongue is the most common lesion in the elderly. It is related to a reduced ability to cleanse the tongue and oral cavity. ${ }^{7}$ An elderly patient can more easily experience coated tongue than young patients. ${ }^{4,6}$ Moreover, changes in diet and physiological function decline in elderly patients. ${ }^{11}$ According to Mosafarri et al., the more a person ages, there is a significant decrease in the Multi Performance Score. ${ }^{8}$

Deposits in the tongue may be removed by brushing with a toothbrush or a tongue scraper. The procedure is done by placing a tongue scraper or toothbrush on the tongue surface's posterior area and moving it towards the anterior direction to avoid impacting microorganisms spreading through by aspiration and entering the lung. ${ }^{12}$ Debris and microorganism accumulation on the coated tongue can be a trigger for aspiration pneumonia. This happens when saliva that is full of microorganisms silently aspires into the lungs. Cleaning the tongue should be done on purpose to reduce and control bacterial overgrowth. Bacterial overgrowth has an impact on systemic disorders and bad breath. ${ }^{6}$ In this study, the highest number of coated tongues in our study population indicated poor oral hygiene.

While the coated tongue is the first usual lesion in the elderly, the second is sublingual varicosities which are described as popular blebs, elevated in blue-purple color, multiple, in the ventral and lateral border of the tongue, or another described as dilated of a sublingual vein, acquired and increased significantly with aging, most at the fifth decade. $^{13,14}$

When sublingual varicosities emerge in a patient, underlying conditions such as portal hypertension, chronic cough, cardiovascular or cardiopulmonary disease, and deficiency of Vitamin $\mathrm{C}$ appear. ${ }^{15}$ The dentist must find a 
lesion immediately and diagnose it as a preventive measure as soon as possible. By performing screening and proper diagnosis, potential systemic diseases and complications may be prevented. ${ }^{16}$

This study's limitation about the normal variant lesion and the underlying systemic disease could not be related since the data was collected retrospectively. Further research is needed to examine the direct connection between the normal variant lesion and underlying systemic disease. ${ }^{10}$

\section{CONCLUSION}

A dentist should improve their ability to diagnose normal variants of oral mucosa to improve early detection and prevent the occurrence of system diseases because the normal variants of oral mucosa structure in the elderly are not only the result of how their body adapts to the environment but also an awareness of the systemic disease that might occur.

\section{Statement of Authorship}

All authors participated in the data collection and analysis and approved the final version submitted.

\section{Author Disclosure}

All authors declared no conflicts of interest.

\section{Funding Source}

The study has no funding support.

\section{REFERENCES}

1. Tosato M, Zamboni V, Ferrini A, Cesari M. The Aging Process and Potential Interventions to Extend Life Expectancy. Clin Interv Aging. 2007;2(3):401-12.

2. Cesar A. Migliorati, Panagakos FS. Concept of Oral Hygiene Maintenance that would Apply for the Different Groups of Patients. Rijeka. 2014;Ch. 12.
3. Abu Eid R, Sawair F, Landini G, Saku T. Age and the Architecture of Oral Mucosa. Age (Omaha). 2012;34(3):651-8.

4. Mahdani FY, Radithia D, Parmadiati AE, Ernawati DS. Prevalence of Oral Mucosal Lesions in Geriatric Patients in Universitas Airlangga Dental Hospital. Acta Med Philipp. 2019;53(5):407-11.

5. Lazos JP, Piemonte ED, Panico RL. Oral Varix: A Review. Gerodontology. 2015;32(2):82-9.

6. Danser MM, Gómez SM, Van der Weijden GA. Tongue Coating and Tongue Brushing: a Literature Review. Int J Dent Hyg. 2003; 1(3):151-8.

7. Kikutani T, Tamura F, Nishiwaki K, Suda M, Kayanaka H, Machida R, et al. The Degree of Tongue-coating Reflects Lingual Motor Function in the Elderly. Gerodontology. 2009;26(4):291-296.

8. Mozafari PM, Amirchaghmaghi M, Moeintaghavi A, Khajedaluee M, Dorri M, Koohestanian N, et al. Oral Health-related Quality of Life in a Group of Geriatrics. J Clin Diagnostic Res. 2015;9(11): ZC52-ZC55.

9. Sudarshan R, Sree Vijayabala G, Samata Y, Ravikiran A. Newer Classification System for Fissured Tongue: An Epidemiological Approach. J Trop Med. 2015;2015(April 2012).

10. García-García AS, Martínez-González JM, Gómez-Font R, SotoRivadeneira Á, Oviedo-Roldán L. Current Status of the Torus Palatinus and Torus Mandibularis. Med Oral Patol Oral Cir Bucal. 2010;15(2).

11. Ogami K, Ueda T, Ryu M, Tajima S, Sakurai K. Evaluation of Factors Associated with Tongue Coating Status in Elderly with Care Needs. Bull Tokyo Dent Coll. 2018;59(3):163-9.

12. Canaan TJ, Meehan SC. Variations of Structure and Appearance of the Oral Mucosa. Dent Clin North Am. 2005;49(1 SPEC.ISS.):1-14.

13. Al-Shayyab MH, Baqain ZH. Sublingual Varices in Relation to Smoking, Cardiovascular Diseases, Denture Wearing, and Consuming Vitamin Rich Foods. Saudi Med J. 2015;36(3):310-5.

14. Madani FM, Kuperstein AS. Normal Variations of Oral Anatomy and Common Oral Soft Tissue Lesions: Evaluation and Management. Med Clin North Am. 2014;98(6):1281-98.

15. Jassar P, Jaramillo M, Nunez DA. Base of Tongue Varices Associated with Portal Hypertension. Postgrad Med J. 2000; 76(899):576-7. 